\title{
Urgent and Emergency Family Physicians in Rural Communities
}

\author{
Katbleen Klink, MD
}

Health reform and the Affordable Care Act have triggered a renewed interest in strengthening access to primary care services, with a focus on ensuring that the nation has appropriately trained physicians practicing where they are needed. There are about 80 primary care physicians per 100,000 people the United States. Not surprisingly, rural areas have a much lower physician-to-population ratio than urban areas and a higher proportion of generalists. ${ }^{1}$ The number and types of physicians needed for optimal health outcomes is key to implementing the triple aim $^{2}$ of improving population health, the experience of care, and costs. Understanding scopes and patterns of practice and settings where family physicians provide care provides a reference point in moving toward full access to high-quality care across the nation.

Described in a policy brief in this issue of the Fournal of the American Board of Family Medicine, staff from the American Board of Family Medicine and The Robert Graham Center analyzed data collected from $>22,000$ family physicians who passed the Maintenance of Certification examination for Family Physicians between 2008 and 2012. They found that $6.7 \%$-almost 1500 of the recertifying family physicians-spend at least $80 \%$ of their time in urgent or emergency care settings. There was an association between greater rurality and a higher percentage of family physicians providing any care in emergency settings. ${ }^{3}$

Family physicians account for one half to two thirds of all physicians in rural areas, and the num-

From The Robert Graham Center, Washington, DC.

Funding: none.

Conflict of interest: none declared.

Corresponding author: Kathleen Klink, MD, The Robert Graham Center, 1133 Connecticut Ave NW, Suite 1100, Washington, DC 20036 (E-mail: kklink@aafp.org).

\section{See Related Article on Page 447.}

ber of specialists diminishes with greater isolation. ${ }^{4}$ This presumably leads to a wider scope of practice to address multiple clinical issues and to provide accessible, comprehensive, continuous, coordinated care that is the promise of family medicine.

Training and deploying the physician workforce to provide services when and where they are needed is complex and varies across regions and circumstances. Because this analysis reveals that rural family physicians spend a substantial proportion of their time in urgent and emergent settings compared with their urban counterparts, attention to the practice environments and patterns, along with the patient population, is particularly relevant.

Scrutiny of the multiple interrelated factors that contribute to the finding of a greater number and percentage of rural compared with urban family physicians practicing in urgent and emergent care may provide perspective on these findings. Factors include, but are not limited to, specialty knowledge, attitudes, and skills of family physicians; workforce needs in underserved and rural locations; available communication and referral networks; and patient demographics in urgent and emergent settings. In addition, the range of health care requirements, including the need for urgent and emergency care in rural settings, offers a wide range of employment opportunities for family physicians that are not available in metropolitan areas.

The flexibility of family physicians is important in providing a broad range of services in response to local needs because patients are not limited to a specific age group, sex, or organ-related complaint. With training in behavioral and social issues related to health, family physicians are well positioned to address the variety of problems that present in urgent and emergent settings. ${ }^{5}$ A significant percentage of emergency visits are for ambulatory care-sensitive conditions, making family physicians exceptionally well prepared. ${ }^{6,7}$ Because family physicians are more likely to provide emergency care in rural settings 
where there are fewer board-certified emergency physicians, they fill a health workforce gap in isolated under-resourced communities. ${ }^{8}$

It is important to note, however, that when the same or similar services are provided episodically rather than in the primary care office, opportunities to develop an ongoing relationship with the patient and to provide comprehensive and preventive care may be missed. ${ }^{9}$ With evidence that coordination of services between emergency and primary care such as health centers improves accessibility, ${ }^{10}$ it is essential to ensure that all physicians, in both isolated as well as urban environments, are supported by referral and communication systems to enhance patient outcomes. Policies that support patientcentered medical home activities within urgent care settings may ameliorate some of the disadvantages of urgent visits.

People seeking care in emergent settings are disproportionately represented by uninsured or underinsured patients, women, children, and minorities, all of whom frequently face barriers to accessing primary care ${ }^{11}$ Rural family physicians, therefore, may be providing access to a disenfranchised population in emergent settings, thus improving needed accessibility for vulnerable populations. $^{12,13}$

Consideration must be given to family physicians' scopes of practice, the associated workforce needs and care settings, demographics of communities served, as well as payment methodologies and coordination among care providers ${ }^{14}$ when determining the appropriate number and types of physicians needed to optimize care as health reform takes shape and the Affordable Care Act is implemented.

The following factors must be considered in workforce planning policies that are intended to advance the triple aim:

1. Appropriate physician specialties and physicianto-population ratios will vary across locales and depend on a range of factors including physician training, skills and experience, available support services, population demographics, and communication networks. One size does not fit all.

2. Family physicians, with broad scopes of practice, provide a flexible resource that is adaptable to local conditions and population needs.

3. Public and private payers should align health services resources and incentives to optimize patient outcomes while considering the context of specific environments, such as rural and frontier areas.

4. Electronic and other communications networks must efficiently and effectively support referral needs among urgent, emergent, and primary care settings to best enhance population outcomes.

\section{References}

1. Petterson SM, Phillips RL Jr, Bazemore AW, Koinis GT. Unequal distribution of the U.S. primary care workforce. Am Fam Physician. 2013;87:Online.

2. Institute for Healthcare Improvement. The IHI triple aim. Available from: http://www.ihi.org/Engage/ Initiatives/TripleAim/Pages/default.aspx/. Accessed April 29, 2014.

3. Peterson L, Petterson S, Phillips RL, et al. One in fifteen family physicians principally provide emergency or urgent care. J Am Board Fam Med. 2014; 27:447.

4. Rosenblatt RA, Chen FM, Lishner DM, Doescher MP. The future of family medicine and implications for rural primary care physician supply. Final report \#125. Seattle: WWAMI Rural Health Research Center, University of Washington; 2010. Available from: http://depts.washington.edu/uwrhrc/uploads/ RHRC_FR125_Rosenblatt.pdf. Accessed May 28, 2014.

5. Gerard WA, Staffer A, Bullock K, Pugno P. Family physicians in emergency medicine: new opportunities and critical challenges. Ann Fam Med. 2010;8: $564-5$.

6. Utah Office of Health Care Statistics. Primary care sensitive emergency department visits in Utah, 2001. Salt Lake City: Utah Department of Health; 2004. Available from: http://health.utah.gov/hda/Reports/ Primary_Care_ERvisits_Utah2001.pdf. Accessed April 15, 2014.

7. McWilliams A, Tapp H, Barker J. Cost analysis of the use of emergency departments for primary care services in Charlotte, North Carolina. N C Med J 2011;72:265-71.

8. Peterson LE, Dodoo M, Bennett KJ, Bazemore A, Phillips RL Jr. Nonemergency medicine-trained physician coverage in rural emergency departments. J Rural Health. 2008;24:183-8.

9. Falik M, Needleman J, Wells B, Korb J. Ambulatory care sensitive hospitalizations and emergency visits: experiences of medicaid patients using federally qualified health centers. Med Care 2001;39:551-61.

10. Hospital emergency departments: health center strategies that may help reduce their use. GAO-11-643T. Washington, DC: US Government Accountability Office; 2011. Available from: http://www.gao.gov/assets/ 130/126188.pdf. Accessed May 28, 2014. 
11. Oster A, Bindman AB. Emergency department visits for ambulatory care sensitive conditions. Med Care 2002;41:198-207.

12. McCusker J, Roberge D, Lévesque JF, et al. Emergency department visits and primary care among adults with chronic conditions. Med Care 2010;48:972-80.

13. Palmer, E, Leblanc-Duchin D, Murray J, Atkinson P. Emergency department use: is frequent use asso- ciated with lack of primary care provider? Can Fam Physician. 2014;60:e223-9.

14. Majority of conditions treated in emergency departments are treatable in primary care clinics. Research activities, April 2012. Rockville, MD: Agency for Healthcare Research and Quality. Available from: http://www.ahrq.gov/news/newsletters/researchactivities/apr12/0412RA3.html. Accessed May 22, 2014. 